\title{
Logistics Distribution Model and Optimization of Home Appliance Retail Chain Enterprise
}

\author{
Wang Qingjun \\ School of Economic and Management \\ Shenyang Aerospace University \\ Shenyang, China
}

\author{
Wei Jian \\ School of Economic and Management \\ Shenyang Aerospace University \\ Shenyang, China
}

\begin{abstract}
A perfect logistics distribution system is not only the guarantee of high-quality service of retail enterprises but also the most important factor influencing the costs and profits of retail enterprises. However, the development of China's logistics industry is not mature and most retail enterprises do not have the experience of establishing their own logistics successfully. Therefore, it is what every home appliance sales enterprise must consider as how to improve the efficiency and level of logistics distribution and reduce logistics costs, because it involves the spending problems in the operation of enterprise. In order to meet the demands of China's home appliance retail chain enterprises and improve the logistics efficiency of China's enterprises, a logistics distribution mode suitable for the actual situation of our country must be developed.
\end{abstract}

Keywords- logistics distribution system; logistics system; retail chain enterprises

\section{INTRODUCTION}

There are relatively more problems in the logistics distribution of China's home appliance retail chain enterprises, and compared with developed countries, the logistics distribution level in China is relatively low, and the logistics capability is relatively backward, frequently causing the damage and loss of products, low efficiency and delay in delivery, etc. which make the logistics distribution cannot meet the demand of retail chain enterprises and the logistics links become obstacles constraining the development of enterprises.

In order to meet the demand of logistics distribution of China's home appliance retail chain enterprises and improve the overall efficiency of logistics distribution of China's home appliance retail chain enterprises, a logistics distribution mode of home retail chain enterprises suitable for the actual situations of our country must be developed and an appropriate enterprise logistics distribution mode must be chosen. An appropriate logistics distribution mode is especially vital for those leading home appliance retail chain enterprises, because they have relatively higher demands on the logistics and distribution, and besides, the sales network of home appliance has spread all over the country.

\section{OPTIMIZATION OF HOME APPLIANCE RETAIL CHAIN ENTERPRISES' LOGISTICS DISTRIBUTION MODE}

\section{A. Applicable Conditions of Various Logistics Distribution Mode}

\section{1) Self-distribution Mode}

In China, most of the large chain enterprises also use this mode. For example, the newly built Taopu distribution center of Shanghai Hualian Supermarket was put into use in 2000, and it is one of the most advanced distribution centers of China's chain enterprises. Now, it has two large distribution centers with a total area of 80,000 square meters, nearly 100 cargo transport vehicles, and the "Zero Inventory" fresh food processing and distribution center of the nation's first-class logistics management, all of which have provided strong support for the rapid expansion of Hualian Supermarkets. Thus, the self-distribution mode is suitable for those relatively strong enterprises with abundant financial resources, and they can improve their core competitiveness through developing their own logistics.

\section{2) Third Party Distribution Mode}

In this distribution mode, chain enterprises will entrust their own distribution business to the logistics company. Therefore, they are usually some small-andmedium-sized enterprises without the strength to build their own logistics centers or some chain enterprises in the development period. The enterprises should understand the business characteristics of the third party logistics companies and make proper adjustment in business, management and distribution.

\section{3) Distributed by Distribution Center}

In this mode, the fundamental role of distribution centers is to make enterprises realize ideal economic benefits through highly centralized procurement and distribution. And generally, it is applicable to large home appliance chain enterprises with strength to build their own logistics center because it has realized unified purchase, unified distribution and dispersed sales so that scale economic benefits can be achieved, and it has advantages in price, quality, management, and banding, etc.

\section{B. Classic Optimization of Home Appliance Retail Chain Enterprises' Logistics Distribution Mode}

1) Optimization of Suning Logistics Distribution Mode 

Mode

a) Increase the Percentage of Self-Distribution

As a leading home appliance chain enterprise, Suning should directly manage and operate its business according to various conditions and factors like its operation scale, product distribution amount of each store and network distribution, etc. And the distribution business should be carried out focusing on the enterprises' sales so as to satisfy the requirement of enterprise sales service to the maximum, provide more flexible and convenient distribution service to each chain stores, and satisfy the demands of chain enterprise so as to maintain good service quality and high service level.

A multifunctional and high-level distribution center with strong distribution capability and a wide range of radiation is important for the realization of modern logistics. Suning should increase the proportion of self distribution and make each of the functional department in the self-distribution mode has a common goal and a higher level of system, which is beneficial for the integral work of chain enterprises' production and sales and satisfy enterprises' demands to the maximum. Besides, it would also help to accelerate the circulation speed of products, realize low inventory or even no inventory in the sales links and reduce the supply shortage rate, thereby improving the operation efficiency of logistics.

\section{b) Self-built Third Party Logistics}

For large home appliance chain enterprises, they are actually controlling the sales terminals, and after they have developed to a certain size, they can often become core enterprises in the supply chain of home appliance industry.

Through establishing logistics companies and developing them into professional third-party provider of logistics service so as to achieve the goal of controlling logistics channels of home appliance, and thereby further consolidate and strengthen the "Chain Lord" status of Suning in the home appliance industry.

With development of scale economy and the increased amount of goods exchange between different regions, there will be two intensive trends: one is the intensification of transportation volume of cargo's location and destination, and another is the intensification of transport path. The "point" formed by productivity layout and each major economic region and the "line", which connects these "points" by various transportations and has dense traffic flow of the same direction, are the formation conditions and network foundation of large home appliance enterprises' logistics.
Steps for Suning to set up the third-party logistics companies. First of all is to establish the Logistics Department, and focus on the enterprises' logistics business and front-line sales and improving the corporate images by using and integrating logistics resources in the society on the basis of existing logistics network. The second is to expand logistics business and try to explore the third party's logistics business and accumulate operation experience by using the network that has already been set up and the great brand effect. Then set up subsidiary logistics companies and develop them into the third-party logistics service providers and finally on the basis of having accumulated a certain amount of the third-party logistics operation experience, separate the Logistics Department and establish an independent accounting business entity.

\section{c) Construction of Distribution Centers}

Currently, the information level of Suning's distribution center is relatively low, and although Suning has mechanic operation and also uses information technology based on the bar code technology and EDI technology, relatively more advanced technologies are not used, e.g. radio frequency technology, GIS technology, GPS technology, TMS technology and WMS technology, etc. Although the SAP management system of information integration is used, the ability of obtaining information automatically is relatively lower, and information is still put into the system manually with high error rate. Because there is no TMS system, the staff still needs to arrange the distribution path according to their familiarity with their own products, delivery vehicles, distribution areas and the distribution of delivered products as well as their amount. There will always be some unreasonable transport phenomenon to the delivery path arranged manually, such as circuitous transportation, repeated transportation and convective transport.

Faced with this unreasonable transportation distribution sorting, the distribution center should carry out information construction and process improvement. When they are summarizing customers' orders after receiving them, they should first determine the type and quantity of distributed products, and then query whether there are products in the existing stocks of products. The distribution center should also order products in advance according to the demands of each customer, the sales of products and the agreements signed with suppliers so as to make preparation for distributing and delivering products, maintain a smooth process and efficient distribution. As shown in Fig. 1

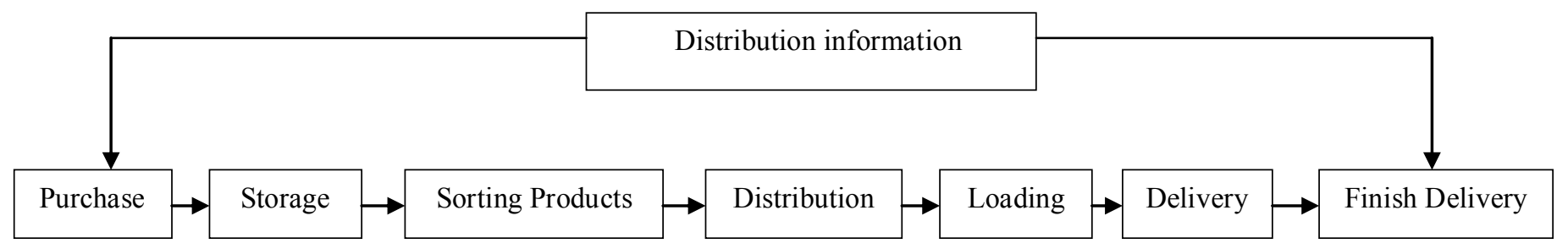

Figure 1. Optimization of Distribution Center Mode

When there are ample commodity resources, after the distribution center has sent an order to the supplier, the supplier should arrange the delivery of products as quickly as possible according to the requirements on the order, and after the distribution center has received 
products, relevant staff needs to sign the delivery list and then inspect the products. Work efficiency will be improved by optimizing the whole distribution process.

Only by strengthening the construction of distribution center reasonably can they enhance Suning's process of error rate at the peak of good import, reduce the delay of delivery and improve service levels.

2) Optimization of Gome Logistics Distribution Mode

a) Integrate Resources and Establish SelfDistribution Mode

In China, most of the chain enterprises choose the mode of self-distribution. Currently, Gome's online performance is on the decline and its real stores are mainly focused on the second-and-third-tier cities, so
Gome should vigorously develop its self-distribution mode. The successful self-distribution mode of Gome is the result of making adjustment in the development, and a great amount of investment is needed in strengthening the constructing and management of self-distribution centers, logistics and facilities, etc. Therefore, capital investment scale, advanced equipment, information technology capacity and management level can all become important factors affecting the logistics distribution mode choice of chain enterprises.

Considering the above two aspects, we can begin to transform the self-distribution mode according to the past of joint distribution patterns abroad and make small-and-medium chain retail enterprises abandon building self-distribution centers but use the joint distribution mode used by relatively mature large chain enterprises like Gome, it is as shown in Fig. 2.

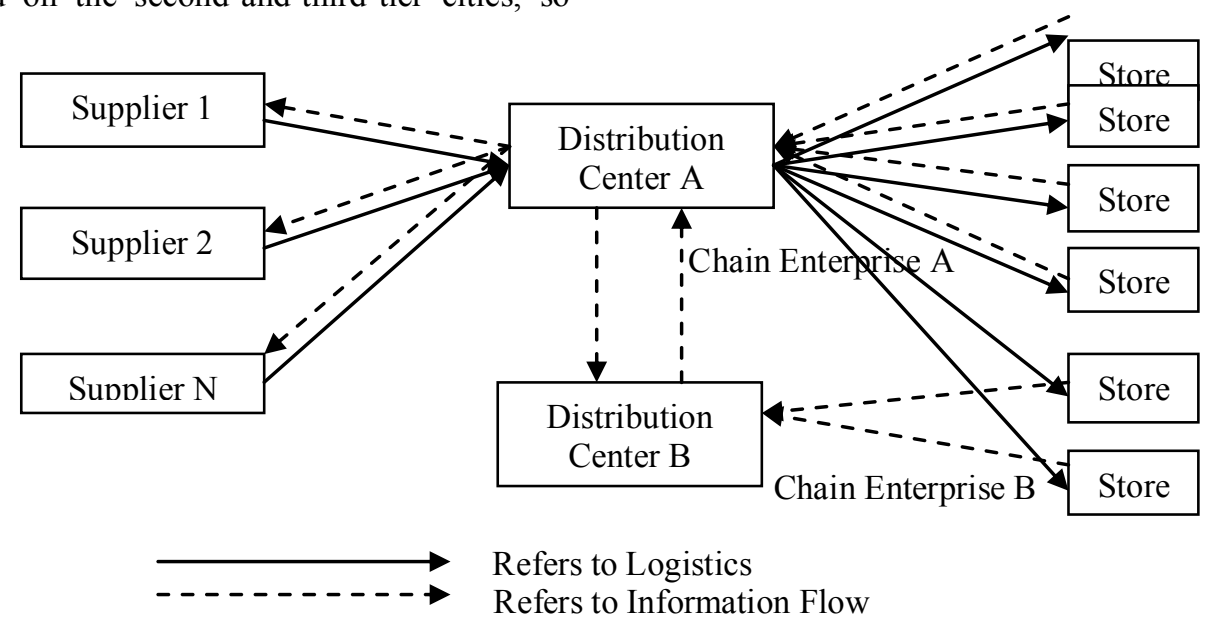

Figure 2. Optimization of Self-Distribution Mode

At present, Gome has already in the mature period, so it can use the self-distribution mode more in the choice of product distribution modes so as to ensure the service quality and have a good relationship with customers. And considering its long-term benefits, it should also undertake the logistics distribution of more small-and-medium-sized enterprises in order to consider itself at the off season and obtain more information resources at the same time. Center

b) Improving Infrastructure at the Distribution

It is the foundation of improving enterprises' distribution capacity to improving logistics distribution equipment. Gome has highly modernized mechanical facility and high automation. And $85 \%$ of the products are processed mechanically, which saves manpower and reduces costs at the same time.

Generally, the distribution facilities in China's chain retail enterprises are relatively backward and are mainly replied on people. In order to make the distribution system automatically and improve the distribution efficiency, Gome has its advantages in the overall competition. Logistics
Gome's mode of setting up self-distribution centers at each region should be "periodic", although it can complete the current distribution service better and satisfy customers' demand for timeliness of delivery. It is still constrained by many of its own uncontrolled factors or factors that are hard to control. Therefore, based on the rapid development of home appliance chain industry, self-distribution mode is used and it belongs to the primary stage of the development of logistics of home appliance chain industry.

3) Optimization of 3Lian Logistics Distribution Mode

\section{a) Develop the Third-Party Logistics Mode}

The third-party logistics enterprises have increases a series of added value like that of products' transportation, inventory circulation and process and improved the delivery efficiency so as to ensure the supply capacity of 3Lina and make full use of the logistics resources of the third-party logistics enterprises. Besides, it can not only reduce and avoid 3Lian's repeat purchase rate of logistics distribution equipment, but also avoid 3Lian's unnecessary expenses on logistics distribution investment and management fees, etc.

From the above analysis, it can be known that for 3Lian, the third-party logistics distribution mode has indeed reduced the investment in distributing fixed 
assets and management fees, so it has the role of providing personalized service. However, the enterprise has various products and different products need different transportation, storage, circulation and processing services, which has increased the difficulty in distribution. Therefore, it is necessary to integrate the third-party logistics enterprises of the same industry into a third-party logistics enterprise association so as to achieve the integration of logistics functions, improve users' service level and reduce the costs of distribution, thus meeting the demand for diversification of chain enterprises' distribution and winning competitive advantages. Meanwhile, the third-party logistics enterprises association makes chain enterprise reduce the difficulty and risks in choosing logistics service providers. Based on the above considerations, the thirdparty logistics enterprise association is adopted to provide services for chain enterprises. It is as shown in Fig. 3:

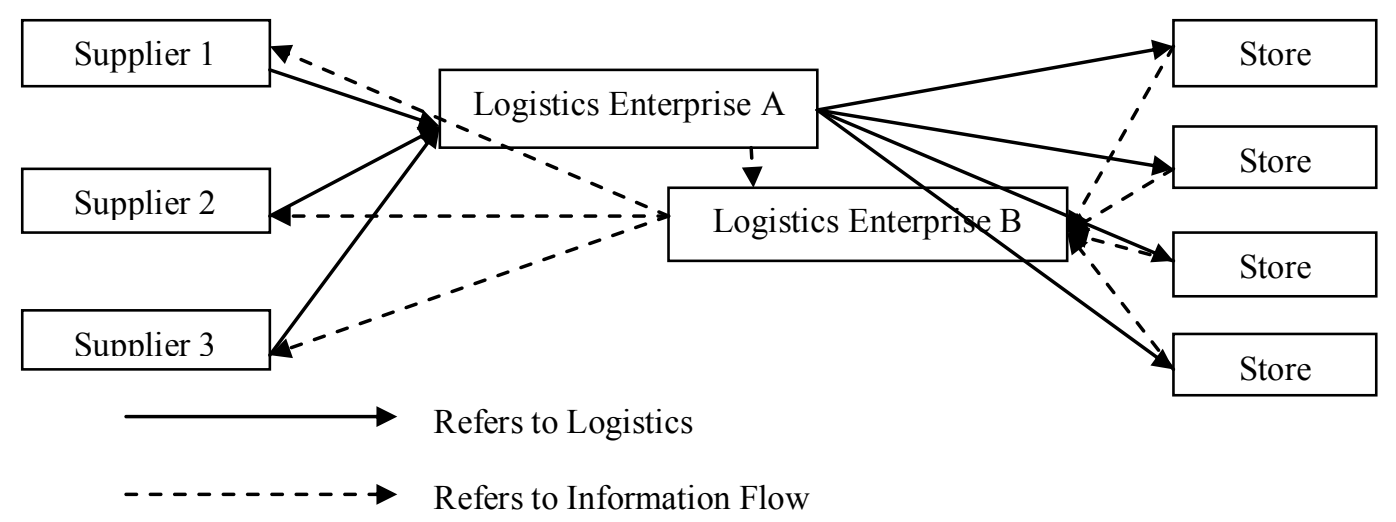

Figure 3. Optimization of the Third-Party Logistics Distribution Mode

As can be seen from Fig. 3, the improved mode is the horizontal integration of the third-party logistics enterprises of the same industry so as to get the several following improvements: (1) The third-party logistics enterprise association has increased a series of added value in the transportation, storage, circulation and processing of chain enterprises' products and improved distribution efficiency so as to ensure the product supply capacity of chain enterprises and it has now already achieved a very professional level in delivery and service. (2) The logistics resources of the third-party logistics enterprises can be fully utilized and unnecessary expenses of chain enterprises on logistics distribution investment and management fees are avoided. (3) The complexity of the chain enterprises' choice of the third- party logistics enterprises has been reduced so that chain enterprises do not need to make the choice according to the distribution demand of different products.

\section{b) Self-built Distribution Center Mode}

Lian should build its own distribution center or use the socialized logistics centers or distribution centers to realize the efficiency of logistics. With the rapid development of the retail industry, especially the chain stores, the circulation has spread wider and stores are chained with their scale become bigger and products become diversified. In this case, in order to maintain the smooth and orderly operation of 3Lian, it is necessary to increase the frequency of making orders and the delivery vehicles, thereby bringing a series of problems like the transportation of products, cumbersome inspection operation, inefficiency and the increase of logistics costs.

\section{CONCLUSION AND PROSPECT}

In China's existing home appliance retail network, the home appliance chain stores have already become the absolute main body in home appliance marketing outlets in terms of amount. The main body of home appliance channels has evolved from department stores, supermarkets and franchised stores to home appliance chain stores and it has been developing with professional scale, comprehensive professional and professional chain stores. Logistics distribution is the guarantee of the normal operation of home appliance chain enterprises. Nowadays, with the rapid development of home appliance chain enterprises, to research the logistics distribution modes of home appliance chain enterprises has great importance for home appliance enterprises to achieve a breakthrough in this development in a deeper and wider range.

In this paper, the following points have been concluded from the research and analysis of Suning's distribution mode: (1) an in-depth understanding of the current domestic situation of logistics distribution and a clear understanding of the main modes of home appliance chain stores' logistics distribution and their defects can promote the development of home appliance enterprises and expand new fields. (2) An in-depth study of China's large home appliance chain enterprises' distribution is made according to the distribution characteristics of large home appliance chain enterprises and a complete logistics distribution system is built. (3) To analyze the distribution modes adopted by Suning and China's large home appliance chain enterprises by connecting the development of logistics distribution modes both at home and abroad and considering the 
status quota of logistics distribution development of China's home appliance chain enterprises and then reasonable solutions are put forward.

In China, most of the chain enterprises choose the self-distribution mode, but it must be suitable to the time and the enterprise itself. Many factors must be considered comprehensively in choosing a distribution mode, for example, the enterprise' s distribution capacity, distribution costs, development strategies, strength at a certain stage, scale of the enterprise, store location, amount and the characteristics of products to be distributed, etc. We should choose a suitable distribution mode according to the actual situation.

Generally, if a retail chain enterprise, which is still at the initial stage of development and with relatively small scale, chooses to build a distribution center of its own, a large amount of investment is needed and it is easy to cause the waste of resources. So it can first complete the delivery of products by using the third-party logistics, and then establish its own logistics distribution center after it has developed to a certain degree. It is a good choice. And for the retail chain enterprise, which is still mature, it can first establish a distribution center and then open chain stores. It is suitable for a small number of large or super retail enterprises.

To build its own logistics distribution or use socialized logistics center or distribution center so as to make the logistics more efficient. With the rapid development of the retail industry, especially the chain stores, the circulation has spread wider and stores are chained with their scale become bigger and products become diversified.

In this case, in order to maintain the smooth and orderly operation of enterprises, it is necessary to increase the frequency of making orders and the delivery vehicles, thereby bringing a series of problems like the transportation of products, cumbersome inspection operation, inefficiency and the increase of logistics costs. The solution of these problems makes it necessary to build an own logistics distribution center or use socialized logistics center or distribution center. Most of the foreign big retail groups not only use the ecommerce for global procurement, but also have large logistics centers or distribution centers generally, through which product information is collected, orders in its dominating areas are processed collectively, and products of each store are distributed together so as to reduce the costs. In building their own logistics centers, retail enterprises in China should make transformation based on the existing logistics facilities so as to save money.

\section{REFERENCES}

[1] Zhang Weixing, Wang Xin. Study on the Current Situation and Optimization of Logistics Distribution of Home Appliance Retail Chain Industry [j]. Enterprise Logistics, 2008(45) : 20-25.

[2] Huang Hongli Research of Logistics Distribution Mode Based on Retail Chain Supermarkets [J]. Modern Economic Information, 2011(5) : 12-15.

[3] Wu Jingdan, Zhang Xihuang. Tentative Analysis of Logistics Distribution Mode Choice of Chain Enterprises [J]. Logistics Technology, 2010(07): 8-10.

[4] Han Yanhui, Li Zhaoxi. Study of Logistics Distribution Mode Choice of Chain Enterprises [J]. Technology \& Methods, 2008(08): 11-15.

[5] Chen Yanhan. Problems in Logistics Distribution of Retail Industry and Its Countermeasures [J]. Commercial Economy Research, 2012(2): 6-9.

[6] Chen Aihu. Primary Discussion about Logistics Distribution of China's Retail Chain Enterprises [J]. Cultural and Educational Information, 2007(01): 15-20.

[7] Yuan Xiangbo. Research of Logistics Distribution Mode of China's Home Appliance Chain Enterprises [J]. Corporation Forum, 2010(07): 9-12.

[8] Zhao Bingbing. Research of Current Development of Logistics of China's Retail Industry [J] Industry Economy, 2011(05): 2027.

[9] Tao Zeng. The Transportation Mode Distribution of Multimodal Transportation in Automotive Logistics [J]. Procedia - Social and Behavioral Sciences. 2013 (11) : 11-16.

[10] M.M. Nassar,A. Elmasry. A study of generalized logistic distributions [J]. Journal of the Egyptian Mathematical Society. 2012(7) 